\title{
Meditaciones y reflexiones universitarias
}

Medardo Ángel Silva Ruales Carrera de Ingeniería Civil UPS - Quito

Caminar con determinada determinación, sin detenerse, sin punto de llegada, hacia una "Tierra nueva" 
El encuentro en el camino con Dios de un Moisés ante la zarza ardiente; el de un san Pablo cuando persiguiendo a los cristianos es derribado de su montura, el de un san Esteban que se deja lapidar porque ha visto al invisible o el de un Jacob , que en el sueño, ha visto subir y bajar por una escalera, a los ángeles, del cielo a la tierra y viceversa, ha cambiado sus vidas y a través de ellos, la de otros muchos, para siempre.

Una zarza que arde sin consumirse, el orgullo humano derribado, una nueva visión de la vida que ilumina todo, una escalera, una herramienta que permite un acceso distinto a la realidad plena del SER, del CONOCER, del HACER, del GUS$T A R$, sin salir de la cotidiana realidad y trascendiéndola a la vez, porque a esa grandeza está llamado el HOMBRE, de ayer, hoy y siempre; lugar de la revelación y comunicación divina.

Es la experiencia de aquel que despierta verdaderamente al camino y es fiel a la llamada de la vía iniciática de la Vida, de la Universidad, por la que entra en un país totalmente nuevo. Todo, absolutamente todo, es diferente. Diferente por su calidad, por su sentido y por el objeto de su conocimiento. Diferente también por la llamada a un cierto comportamiento y a una cierta relación con los demás y con toda la vida.

El principiante en el camino como el gestor de una nueva Universidad pisa un suelo nuevo, lleno de sorpresas, de tentaciones y de peligros. Muchas cosas le asustan, otras le parecen profundamente familiares. Al principio está, naturalmente, suspendido entre dos universos, entre la promesa y las exigencias de lo nuevo y el peso del antiguo mundo habitual, entre el espíritu de aventura que le empuja hacia lo inexplorado y la necesidad de seguridad que le remite a sus costumbres; entre el impulso de fuerzas aún desconocidas y la fidelidad a los antiguos valores. Todo depende en este momento de una decisión inequívoca y de la tenacidad en Ilevarla a cabo. Hay que atre- verse a salir de las estrechas fronteras de un orden tranquilizador para entrar en el vasto terreno de la libertad, que no posee ningún sistema de seguridad; aceptar el riesgo de ser infiel al orden y a las leyes establecidas para ser fiel a lo inaudito, cuya promesa y obediencia brota del corazón del Ser esencial; abandonar la red de relaciones humanas, superficiales, bien organizadas, para afrontar la soledad que va pareja con la profundidad; profundidad donde sólo encuentran un lugar aquellos contactos que dejan resonar su voz secreta. Quien ha despertado al camino se convierte en ciudadano de otro reino, que no es de este mundo, sino el de su origen hacia el que comienza a retornar. Sus únicos y auténticos lazos le unen a aquellas personas que él siente son sus hermanos y hermanas en el SER, en el CONOCER, en el HACER y en el GUSTAR.

El país nuevo en que entra es siempre un país de revolucionarios. Los sistemas existentes sólo son reconocidos si preparan una renovación. Si oprimen lo que supone el futuro son combatidos. El hombre iniciado es un foco de confusión. Nada le inmoviliza, ni incluso, y sobre todo, el hecho de encontrar, en el curso de su evolución, el objeto de su constante búsqueda. El también da la razón a la sabiduría búdica: "Si llegas a un lugar en el que no encuentras a Buda -dice- vete más lejos. Pero si llegas a un lugar en el que encuentras a Buda, aléjate más".

La vida iniciática como la vida universitaria es siempre sorprendente y peligrosa, para los enemigos, para los amigos y para uno mismo.

Sin temor a equivocarme, así concibo, al presente, dentro del proceso que estamos viviendo al interior no sólo de nuestra Institución de Educación Superior, sino, también aplicable, a nivel de nuestro país y claro está, a nivel de nuestras propias vidas individuales, familiares, académicas, sociales, eclesiales y mundiales, que nos llevan a hablar de una "época de cambio y un cambio de 


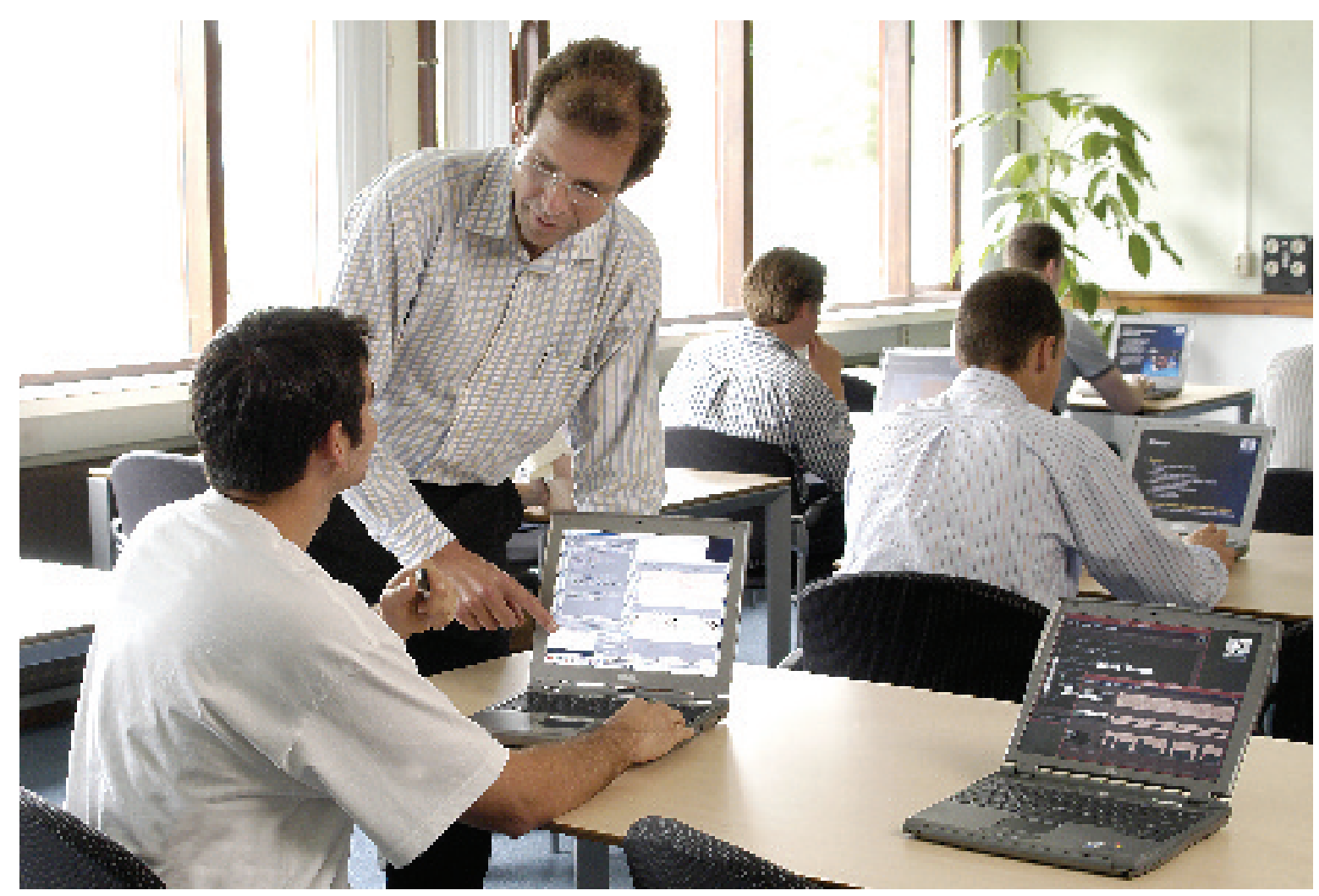

época", que desde hace un medio siglo atrás liderado por las ciencias y técnicas llamadas de punta se apoyan en el lenguaje informatizado a través de la fonología y las teorías lingüísticas, los problemas de la comunicación, la cibernética, las álgebras modernas, la informática, los ordenadores, sus lenguajes, la búsqueda de compatibilidades entre lenguajesmáquinas, los problemas de memorización, los bancos de datos, la telemática y la puesta a punto de terminales inteligentes.

Permítaseme aquí hacer otra comparación: La experiencia de conducir un auto último modelo, equipado con tecnología de punta: automático, con computadora incorporada, con rastreador satelital e incluido un mapa virtual digital de carreteras, que nos invita en él, a "caminar" sin detenernos y sin punto de llegada por la vida propia y por la vida de todos. ¿Qué tal? ¡Bien! Verdad.

Así, nuestra Institución, ha ingresado en su conjunto y comunitariamente en un "escenario nuevo", el mundo universitario, el mundo de la "academia", en una época cultural también nueva, y ha entrado sin salir del mundo en un nuevo mundo, el mundo del "claustro universitario", el de la "Comunidad Educativa Universitaria", "real y virtual", con sencillez, con pie firme, con profundo respeto, con admiración y hasta con sustos.

Viene participando internamente en ya cinco encuentros nacionales de "planificación y organización universitaria" y en otros tantos, internacionales, a nivel de las Instituciones Universitarias Salesianas (IUS). Han sido, cada uno a su momento, verdaderos "Pentecostés", pasos del "Espíritu" para nuestra Institución, de mano de un equipo de expertos asesores, y vivido por quienes hemos participado en ellos, a lo Moisés, a lo san Pablo, a lo Esteban, a lo Jacob, esto es, como una oportunidad para crecer, para unirnos y para aprender a trabajar en equipo, generosamente.

Las preguntas de rigor que han ocupado nuestras mentes y corazones, han sido: ¿Por qué y para qué hoy la Universidad y Politécnica y Salesiana? (Objetivos); ¿Qué es la Universidad? ¿Qué dice de sí la 
Universidad? ¿Qué hace la Universidad? ¿Dónde esta hoy la Universidad? ¿Existe todavía la Universidad? ¿Cuál es la natural vocación educativa de la Universidad? (Contenidos); ¿A quién responde la Universidad hoy? ¿A la sociedad, al mercado, al hombre? ¿Quién hace la Universidad? ¿Qué clase de profesionales entrega a la sociedad? (Actores) y finalmente, ¿Cómo debe ser la Universidad? ¿Cómo se hace y aprende hoy en la Universidad? (Metodologías).

Desde el 2004, cuenta definitivamente con la "Carta de Navegación" y a manera de cascada, ha generado una serie de documentos, instrumentos, normativas y herramientas, en las que están deline- adas con claridad meridiana, desde un diagnóstico de la realidad, pasando por los desafíos, con una clara visión y misión institucional de lo que queremos, hasta los sueños, y las herramientas "reales y virtuales" con las que deberíamos estar todos bien familiarizados, a fin de alcanzar una sintonía tal, que nos permita actuar sincronizadamente, para no desentonar ni con el ambiente creado interno ni con el externo, donde se desenvuelve nuestra institución de manera sinfónica.

¡Despertemos! Es tiempo de caminar, de bien en mejor, con determinada determinación.

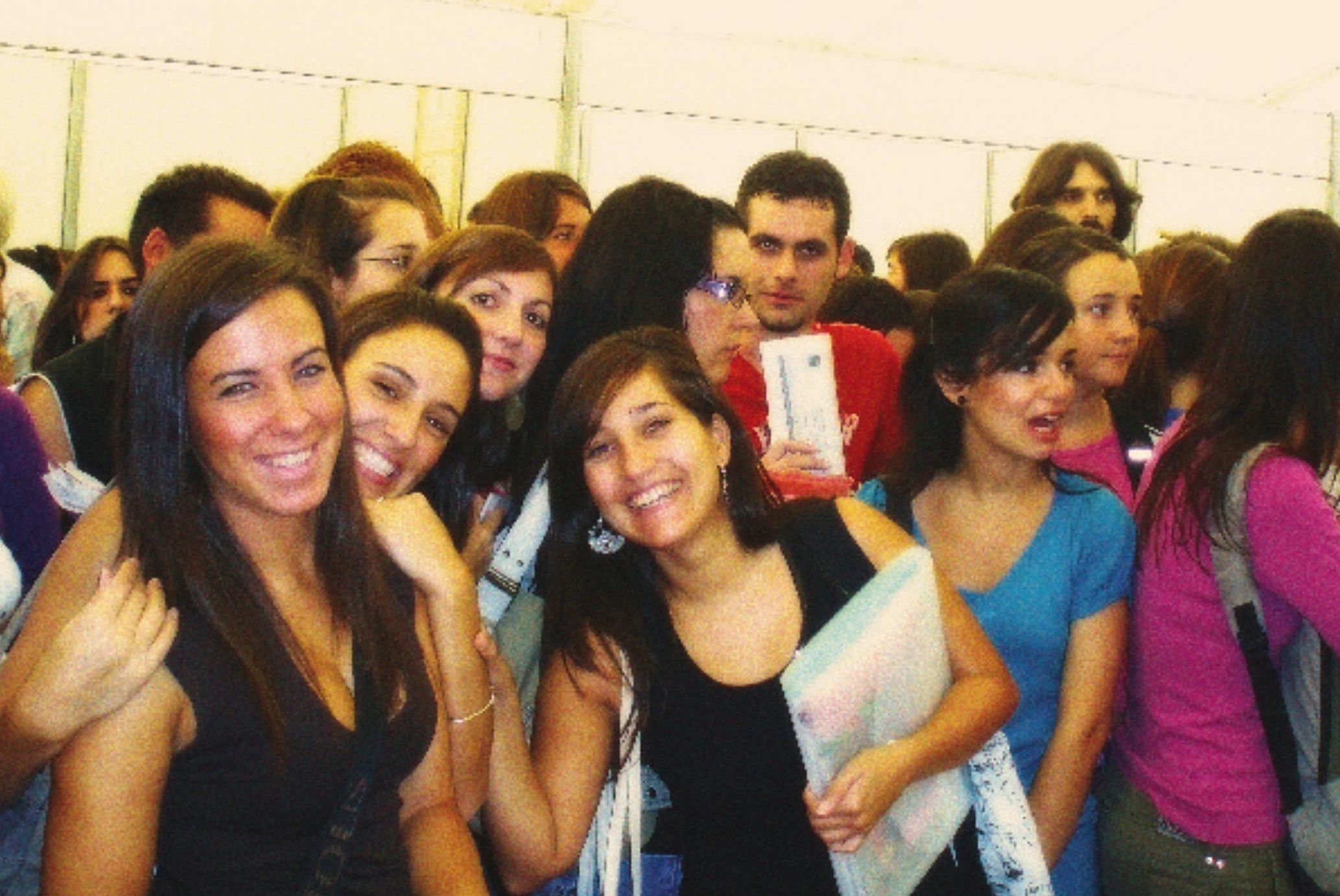

